\title{
Discovery of serum biomarkers of alcoholic fatty liver in a rodent model: C-reactive protein
}

\author{
Shu-Lin Liu', Chun-Chia Cheng ${ }^{2,3}$, Chun-Chao Chang ${ }^{4}$, Fu-Der Mai ${ }^{2,5,6}$, Chia-Chi Wang ${ }^{7}$, Shui-Cheng Lee ${ }^{3}$, \\ Ai-Sheng $\mathrm{Ho}^{8}$, Ling-Yun Chen ${ }^{1^{*}}$ and Jungshan Chang ${ }^{2,5,9,10^{*}}$
}

\begin{abstract}
Background: Excessive consumption of alcohol contributes to alcoholic liver disease. Fatty liver is the early stage of alcohol-related liver disease. The aim of this study was to search for specific serological biomarkers of alcoholic fatty liver (AFL) compared to healthy controls, non-alcoholic fatty liver (NAFL) and liver fibrosis in a rodent model.

Methods: Serum samples derived from animals with AFL, NAFL, or liver fibrosis were characterized and compared using two-dimensional differential gel electrophoresis. A matrix-assisted laser desorption ionization-time of flight tandem mass spectrometer in conjunction with mascot software was used for protein identification. Subsequently, Western blotting and flexible multi-analyte profiling were used to measure the expressions of the putative biomarkers present in the serum of animals and clinical patients.
\end{abstract}

Results: Eight differential putative biomarkers were identified, and the two most differentiated proteins, including upregulated C-reactive protein (CRP) and downregulated haptoglobin ( $\mathrm{Hp}$ ), were further investigated. Western blotting validated that CRP was dramatically higher in the serum of AFL compared to healthy controls and other animals with liver disease of NAFL or liver fibrosis $(p<0.05)$. Moreover, we found that CRP and Hp were both lower in liver fibrosis of TAA-induced rats and clinical hepatitis $C$ virus-infected patients.

Conclusion: The results suggest that increased levels of CRP are an early sign of AFL in rats. The abnormally elevated CRP induced by ethanol can be used as a biomarker to distinguish AFL from normal or otherwise diseased livers.

Keywords: alcoholic fatty liver, biomarker, C - reactive protein, haptoglobin, two-dimensional differential gel electrophoresis

\section{Background}

Excessive alcohol consumption affects lipid metabolism in the liver $[1,2]$, contributing to the development of alcohol-related liver diseases. There are three main types of alcohol-related liver disease, these are: alcoholic fatty liver (AFL), alcoholic hepatitis, and alcoholic cirrhosis. AFL is the early stage of alcohol-related liver diseases. Therefore, identifying putative serum biomarkers of AFL for early and accurate diagnostic methods is vital.

Histological assessment of liver biopsy specimens remains the gold standard for determining alcohol-

\footnotetext{
*Correspondence: chenly@csmu.edu.tw; js.chang@tmu.edu.tw

'Institute of Biochemistry and Biotechnology, Chung Shan Medical

University, Taichung, Taiwan

${ }^{2}$ Graduate Institute of Medical Sciences, College of Medicine, Taipei Medical

University, Taipei, Taiwan

Full list of author information is available at the end of the article
}

related liver disease. However, the methodology of histological assessments needs to overcome several drawbacks such as its invasive character and sampling error [3]. Moreover, it has difficulty in distinguishing AFL from non-alcoholic fatty liver solely through a histological assessment. On the other hand, predicting ethanolinduced oxidative stress and tissue injury in the liver require particularly sensitive markers [4]. A previous study suggested that glutamyl-transpeptidase (GGT) and alanine aminotransferase (ALT) are biomarkers for diagnosing alcoholic liver disease [5]. Several reports proposed that serum $C$-reactive protein (CRP), tissue polypeptide-specific antigen (TPS), and interleukin- 6 are noninvasive biomarkers of alcoholic hepatitis [6-10]. Nevertheless, a reliable biomarker to predict the early 
stage of alcoholic hepatitis, i.e., AFL, and to distinguish AFL from other types of liver disease is needed.

A proteomics strategy based on two-dimensional differential gel electrophoresis (2D-DIGE) [11] allows for the simultaneous resolution of thousands of proteins from samples with high precision and replication. 2D-DIGE was used to screen and determine putative biomarkers of many diseases [12-15]. Those protein samples of interest displayed on 2D-DIGE can be extracted and acquired from gels for identification and further investigation. In total, we discovered eight differential proteins associated with AFL using 2D-DIGE, including the most differentiated proteins: CRP and haptoglobin $(\mathrm{Hp})$.

This study revealed that CRP is a novel early biomarker of alcohol-induced fatty liver, and that CRP and Hp were both particularly decreased with liver fibrosis. In conclusion, we present CRP as a surveillance marker of alcoholinduced fatty liver in a rodent model, which may help diagnose early alcohol-induced pathophysiological alterations in clinical practice.

\section{Materials and methods}

\section{Animal model and sample preparation}

Animal experimentation was performed according to approved procedures of the Institute of Nuclear Energy Research, Atomic Energy Council, Taoyuan, Taiwan (approval no.: 98053). Wistar rats were used to generate animals with AFL, non-AFL (NAFL), and liver fibrosis. AFL rats $(n=6)$ were orally fed $5 \mathrm{ml}$ of a $36 \%$ alcohol solution for 4 weeks $(6 \mathrm{~g} / \mathrm{kg} /$ day $)$ [16]. For rats with NAFL, animals were given food containing $60 \%$ fructose $(n=4)$ or $45 \%$ fat $(n=6)$ for 12 weeks. The liver-fibrosis rats $(n=6)$ were fed $0.04 \%$ thioacetamide (TAA)-containing drinking water for 12 weeks. Control animals were fed normal diets with no additives in their food $(n=7)$. Sera and liver tissues were collected for further investigation.

\section{Clinical serum collection}

The sera of healthy volunteers $(n=16)$, patients with nonalcoholic steatohepatitis $(n=19)$ and patients with hepatitis $\mathrm{C}$ virus (HCV)-infected liver fibrosis $(n=17)$ were obtained from Cheng Hsin General Hospital in Taiwan (approval no. 97016). A liver biopsy and subsequent histological examination were used to assess the stage of liver fibrosis according to the Metavir classification, and also to determine the fatty change and modified HAI grade. A liver biopsy was not performed in healthy controls due to ethical issues.

\section{D-DIGE}

Each $50 \mu \mathrm{g}$ of protein from a normal control or AFL rat was labeled with 400 pmol of Cy3 or Cy 5 and the internal pooled standard $(100 \mu \mathrm{g})$ was labeled with $800 \mathrm{pmol}$ of Cy2 for $30 \mathrm{~min}$. The three labeled samples were pooled together for analysis. IPG strips $(18 \mathrm{~cm})$ at $\mathrm{pH}$ 4 7 for the first-dimension IEF (Ettan IPGphor System, GE Healthcare) and $12.5 \%$ polyacrylamide gels for the second dimension were used to separate serum proteins. The Cy2, Cy3, and Cy5-labeled images were acquired on a Typhoon TRIO Variable Mode Imager (GE Healthcare) using 488-, 532-, and 633-nm lasers with respective emission filters of 520, 532, and $670 \mathrm{~nm}$. Images were analyzed using DeCyder 6.5 software (GE Healthcare) to select the differential proteins. Protein spots of interest were selected according to an independent Student's t-test with a significant value of $<0.05$.

\section{Protein identification}

In-gel digestion and MALDI-TOF MS analysis were performed as previously described [13].

\section{Western blotting}

Each serum sample was diluted 1: 1 with a sodium dodecylsulfate (SDS) buffer containing $50 \mathrm{mM}$ of Tris-Cl, $8 \mathrm{M}$ urea, 30\% glycerol, $2 \%$ SDS, $20 \mathrm{mM}$ of dithiothreitol, and $0.1 \%$ bromophenol blue. A 4\% 12\% SDS- polyacrylamide gel electrophoresis (PAGE) (Invitrogen) was performed to separate the proteins. The iblot (Invitrogen) was used to transfer proteins to a polyvinylidene difluoride (PVDF) membrane. After using 0.5\% milk to blot the PVDF membrane for $30 \mathrm{~min}, \mathrm{CRP}$ and $\mathrm{Hp}$ were detected by a mouse anti-CRP immunoglobulin G (IgG) (Affinity BioReagents) and a mouse anti- Hp IgG (Sigma) for at least $1 \mathrm{~h}$ respectively. The second antibody conjugated with horseradish peroxidase (HRP) was incubated for $1 \mathrm{~h}$ at room temperature. The membranes were washed three times in phosphate-buffered saline (PBS; $10 \mathrm{mM}$ sodium phosphate (pH7.4) and $0.9 \% \mathrm{NaCl}$ ) between adding antibodies. The Imaging System (Gel Doc XR System, Bio-Rad) was used to acquire images depending on a moderate exploration time and to semi-quantify protein expressions.

\section{Measurement of CRP and Hp concentration}

Flexible multi-analyte profiling (xMAP) was performed to measure serum concentrations of CRP and $\mathrm{Hp}$ in clinical samples using the commercial Bio-Plex Pro Human Acute Phase 4-Plex Panel (Bio-Rad). The measurment procedure followed instructions in the manual.

\section{Statistical analysis}

The statistical software, SPSS, was used to calculate the significance according to Student's t-test. Significance ( $p$ value) was accepted as $<0.05$.

\section{Results}

\section{Animal models}

Each experimental animal bearing a specific liver disease, namely: AFL, NAFL and, liver fibrosis was analyzed and 
compared. To ensure the correct establishment of the animal models, several indicators in the serum including aspartate aminotransferase (AST), alanine aminotransferase (ALT), total bilirubin (TBIL), total cholesterol (TCHO) and triglyceride (TG) were measured and compared (Table 1). Levels of AST, ALT, and TBIL increased in $\mathrm{LF}$ rats $[199 \pm 37 \mathrm{U} / \mathrm{L}(p<0.01), 74.4 \pm 19 \mathrm{U} / \mathrm{L}(p<$ $0.01)$, and $0.84 \pm 0.10 \mathrm{mg} / \mathrm{dl}(p<0.05)$, respectively] compared to those in normal controls (AST $154 \pm 25 \mathrm{U} / \mathrm{L}$; ALT $56 \pm 15 \mathrm{U} / \mathrm{L}$; and TBIL $0.70 \pm 0.06 \mathrm{mg} / \mathrm{dl})$, indicating that the liver function of LF rats was impaired. However, no significant changes in these three serum indicators in AFL and NAFL were observed. Other indicators, TCHO and TG, were measured to observe lipid accumulation in the liver. An increased TG level was observed only in the group of rats fed the high concentration of fructose $(91 \pm 14 \mathrm{mg} / \mathrm{dl}, p<0.05)$ compared to other rats fed different diets, but the TCHO level remained unchanged. These results show that AST, ALT, and TBIL increased in the serum of LF rats, and TG increased in rats that were fed a high level fructose. Therefore, these existing serum indicators so far could not be used to distinguish AFL from the normal controls, which means that finding differential biomarkers of AFL is vital.

On the other hand, we observed that there was no significant difference in the morphology of livers among normal, AFL and, NAFL rats except for rats with liver fibrosis showing excess scars (Figure 1). To more-deeply assess our established rodent models using histological examinations, the results showed that livers of rats with AFL appeared to specifically be filled with macrovesicular fat within hepatocytes compared to normal controls according to histological staining with hematoxylin and eosin (H\&E) (Figure 1), demonstrating that ethanol treatment induced lipid accumulation in the liver. Furthermore, signs of focal necroinflammation were absent from the liver tissues of rats with AFL (Figure 1).

\section{Discovery of AFL biomarkers using 2D-DIGE}

In order to explore the signature molecular biomarkers of AFL, a proteomic methodology, 2D-DIGE, described above "Materials and methods" was performed to analyze individual serum from two normal controls or two AFL rats shown on Figure 2A to search for putative biomarkers of AFL. In the 2D-DIGE analysis, Cy3 and Cy5 were used to individually label serum samples from normal controls and AFL rats. For sample normalization, Cy2 was used to label the internal standard including $50 \%$ of normal and $50 \%$ of AFL rats. The protein image was presented as shown in Figure 2B. Normal control sera were labeled with $\mathrm{Cy} 3$ and appeared colored green in the gel. Samples derived from rats with AFL were pre-labeled with Cy5 and showed as a red color in the gel. Eight differential proteins including CRP, Hp, afamin, alpha-fetoprotein (AFP), inter-alpha-inhibitor $\mathrm{H} 4$ heavy chain (ITIH4), serine protease inhibitor Kazaltype 5 (SPINK5), heak shock protein $75 \mathrm{kDa}$ (HSP75), and vitamin $\mathrm{D}$ binding protein prepeptide (VDBP) were acquired according to the statistical analysis with significant $p$ values $(t$-test, $p<0.05)$, and an intensity change ratio of $>1.2$-fold calculated with DeCyder software. The location of each protein is shown in Figure 2C. When using a stereopicture and detailed gel images to present the protein expressions of differential biomarkers (Figure 3), CRP, AFP and afamin were increased higher in the serum of AFL rats, and Hp, ITIH4, SPINK5, HSP75, and VDBP were conversely lower. In particular, Hp, ITIH4 and SPINK5 had a series of spots nearby, but the protein expressional trends were still the same. We speculated that post-translational modification would not affect or influence the protein expression. Essentially, we identified protein spots by comparing the mass spectrum obtained from MALDI-TOF MS coupled with the NCBI database. The proteins identified are shown in Table 2. According to the set calculation in the DeCyder software, the upregulation $(+)$ is presented

Table 1 Levels of some clinical serum indicators in the animals

\begin{tabular}{|c|c|c|c|c|c|}
\hline Indicators & $\begin{array}{c}\text { Normal } \\
(n=7)\end{array}$ & $\begin{array}{c}\text { AFL } \\
(n=6)\end{array}$ & HF-NAFL $(n=4)$ & HL-NAFL $(n=6)$ & $\begin{array}{c}\mathrm{LF}^{\S} \\
(n=5)\end{array}$ \\
\hline BW (g) & $270 \pm 5^{\natural} / 457 \pm 14^{\S}$ & $275 \pm 3^{n}$ & $418 \pm 28^{\S}$ & $565 \pm 29^{\xi_{1, *}}$ & ND \\
\hline AST (U/L) & $154 \pm 25$ & $148 \pm 34^{c}$ & $164 \pm 31$ & $181 \pm 63$ & $199 \pm 37^{*}$ \\
\hline $\mathrm{ALT}(\mathrm{U} / \mathrm{L})$ & $56 \pm 15$ & $41 \pm 13^{c}$ & $48 \pm 17$ & $57 \pm 22$ & $74 \pm 19^{*}$ \\
\hline $\begin{array}{c}\text { TBIL } \\
(\mathrm{mg} / \mathrm{dl})\end{array}$ & $0.70 \pm 0.06$ & $0.62 \pm 0.09^{a, b}, c$ & $0.78 \pm 0.04$ & $0.75 \pm 0.05$ & $0.84 \pm 0.10^{*}$ \\
\hline $\begin{array}{c}\mathrm{TG} \\
(\mathrm{mg} / \mathrm{dl})\end{array}$ & $51 \pm 16$ & $58 \pm 10^{a}$ & $91 \pm 14^{* *}$ & $56 \pm 11$ & $48 \pm 14$ \\
\hline $\begin{array}{l}\mathrm{TCHO} \\
(\mathrm{mg} / \mathrm{dl})\end{array}$ & $61 \pm 10$ & $68 \pm 8$ & $72 \pm 10$ & $71 \pm 12$ & $61 \pm 17$ \\
\hline
\end{tabular}

BW, body weight; AST, aspartate aminotransferase; ALT, alanine aminotransferase; TBIL, total bilirulin; TG, triglyceride; TCHO, total cholesterol; AFL, alcoholic fatty liver; HF-NAFL, high fructose-induced non-alcoholic fatty liver; HL-NAFL, high lipid-induced non-alcoholic fatty liver; LF, liver fibrosis. Indicators for predicting liver function include GOT, GPT, and bilirubin and for predicting fat cells include triglyceride and cholesterol. Rats were treated before the age of 6 weeks and sacrificed by the ages of " 10 and ${ }^{\S} 18$ weeks. ND, Non-detection. The $p$ value was calculated according to Student's $t$-test. ${ }^{*} p<0.05$ and ${ }^{* *} p<0.01$ as compared to normal controls. A significant change $(p<0.05)$ was also determined for AFL rats compared to ${ }^{\mathrm{a} H F-N A F L,}{ }^{\mathrm{b}} \mathrm{HL}-\mathrm{NAFL}$, and ${ }^{\mathrm{C} L F}$ rats. 


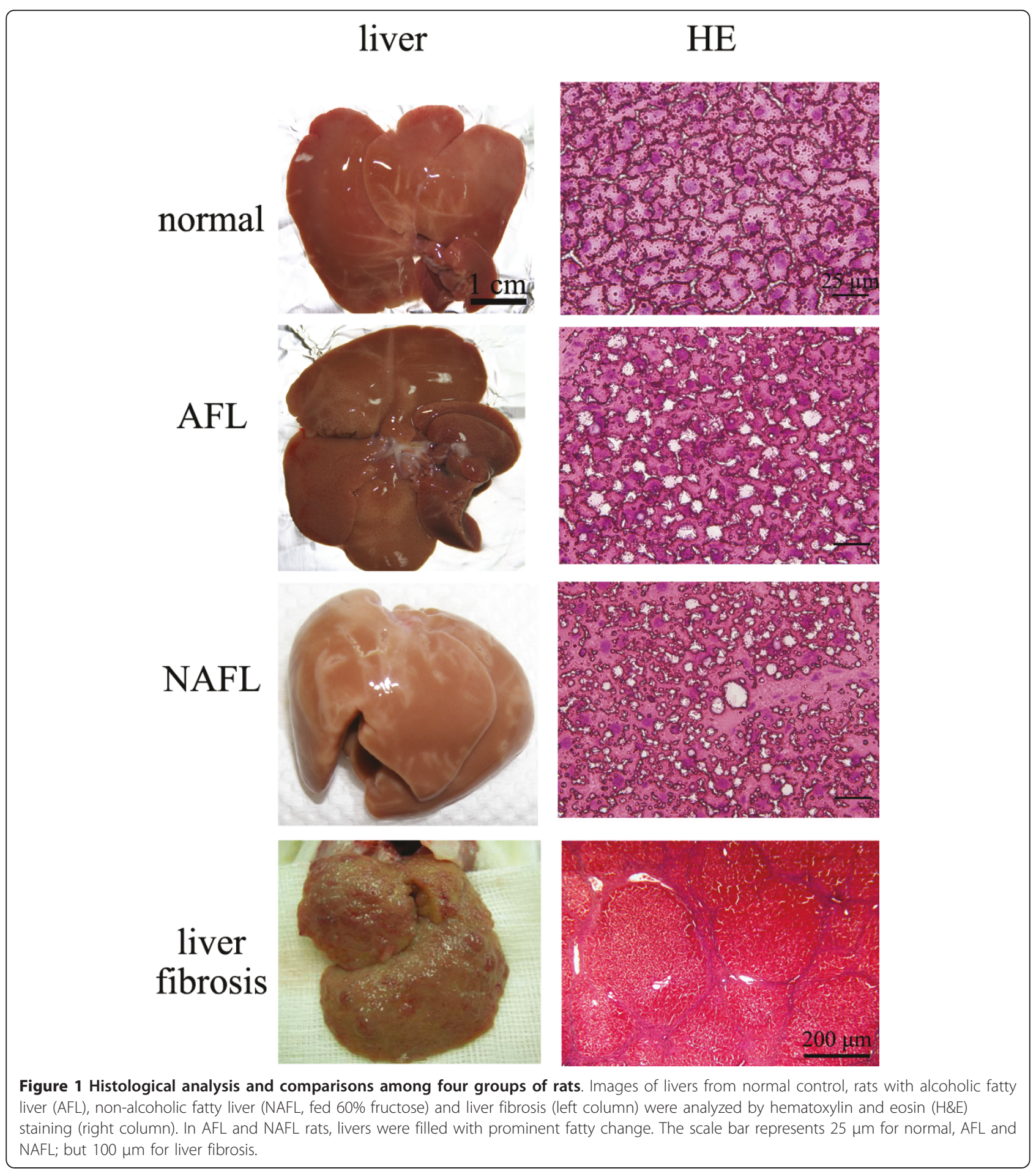

as the levels of AFL divided by that of normal control, and the downregulation (-) is presented as the levels of normal control divided by that of AFL. The results demonstrated that CRP and Hp were dramatically upand downregulated, respectively (CRP: +4.71 -fold; HP: -11.54-fold, Table 2).

\section{CRP and Hp validation}

We were interested in characterizing the role of CRP and Hp in AFL due to significant changes in their protein expressions. In the process of Western blotting, we precisely controlled the loading protein to $20 \mu \mathrm{g}$, and the total protein stained by SYPRO Ruby was used as a 


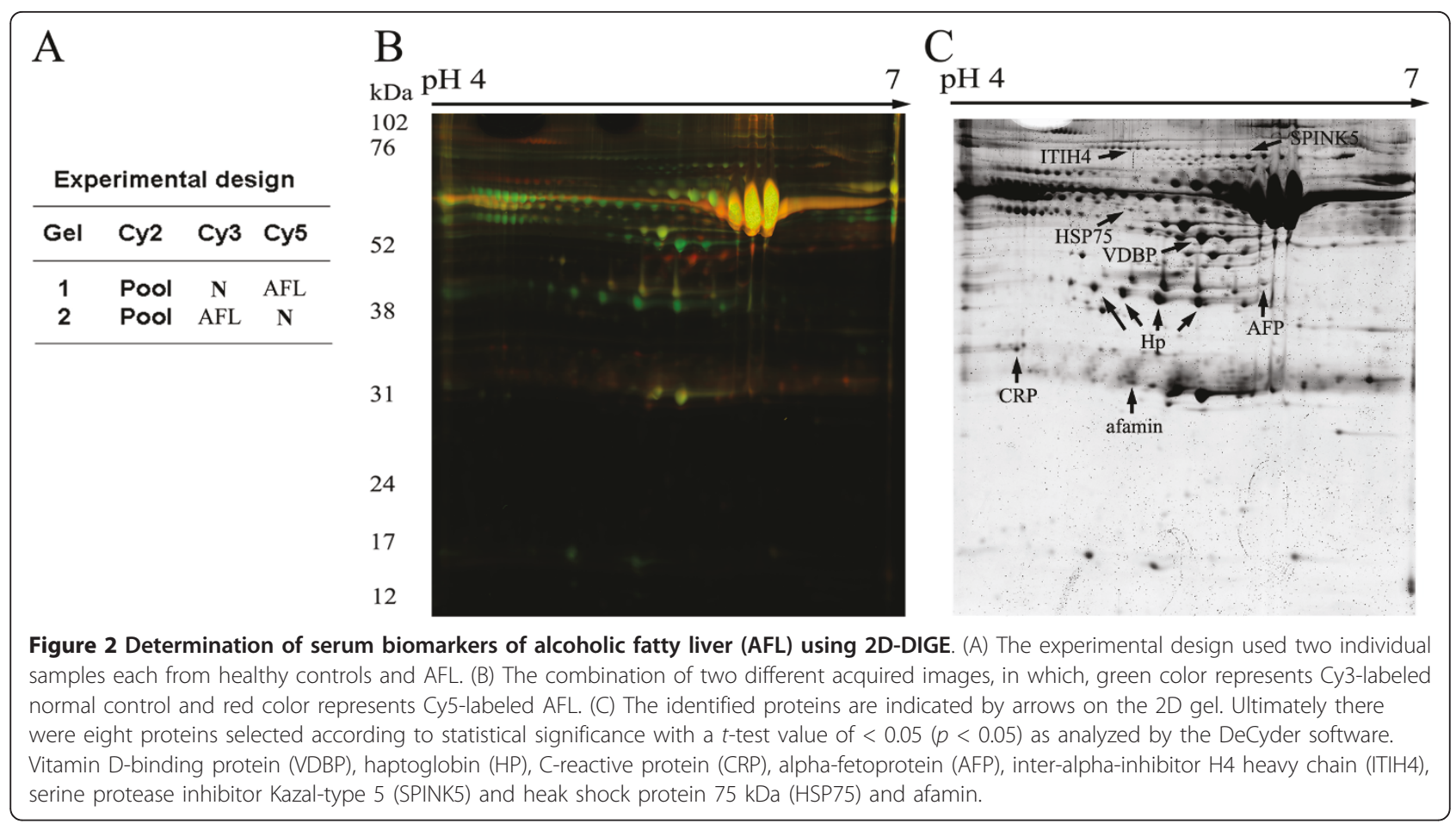

loading standard (data not shown). Figure $4 \mathrm{~A}$ and $4 \mathrm{~B}$ show that CRP particularly increased in AFL rats compared to all other groups including normal rats and rats with NAFL disease or liver fibrosis (all $p<0.05$ ), demonstrating that CRP is a putative biomarker of AFL. Meanwhile, Hp did not significantly decrease in the serum of AFL rats according to the Western blotting analysis (Figure 4A). Interestingly, we observed that CRP and $\mathrm{Hp}$ were both downregulated in the serum of liver fibrosis rats compared to normal, AFL, and NAFL rats (Figure 4B, C, all $p<0.05$ ). On the other hand, we also examined the level of alpha1 antitrypsin (AAT) to exclude the elevation of CRP derived from ethanolinduced gastrointestinal inflammation. The results showed that AAT levels were not increased in the serum of AFL rats compared to healthy controls (Figure 4D).

Moreover, in order to evaluate the decreased expressions of CRP and $\mathrm{Hp}$ in the serum of liver fibrosis rats, we measured serum CRP and Hp concentrations in clinical patients with non-alcoholic steatohepatitis (NASH) and $\mathrm{HCV}$-induced liver fibrosis compared to healthy controls. Table 3 shows that CRP and Hp were lower in patients with $\mathrm{HCV}$-induced liver fibrosis, which was consistent with the results demonstrated by Western blotting, suggesting that CRP and $\mathrm{Hp}$ are reliable biomarkers of liver fibrosis as downregulated proteins. Interestingly, we found that serum $\mathrm{Hp}$ was elevated in NAFL rats, but lower in NASH patients, implying that the expression of Hp may vary between the nonnecroinflammatory stage (NAFL) and necroinflammatory stage (NASH).

\section{Discussion}

The aim of this study was to determine the putative serological biomarkers of AFL using 2D-DIGE, and then these candidate markers were validated by Western blotting. To characterize AFL disease markers, our experimental strategy was first to induce patholophysiological abnormalities in animals by administering alcohol, high calories of compounds such as: fructose or fats, and drinking water with TAA, a fibrosis-inducing chemical. Under this experimental platform, rats should have developed AFL, NAFL and liver fibrosis, allowing us to determine the signature biomarkers for AFL, which is the early stage in the alcohol-induced liver disease. From our rodent models, we determined that CRP levels were significantly elevated in the serum of rats with AFL, presumably as a reliable biomarker compared to that in livers of healthy or sick rats with other liver diseases.

Indeed, CRP increases in other conditions, such as inflammation, obesity $[17,18]$, and cardiovascular disease $[19,20]$; however, it is also a elevated AFL-induced protein in rats as discovered in this study. Here, our discovery provides a hint that CRP can be used to distinguish AFL from normal or otherwise diseased livers. A previous report indicated that CRP is a non-invasive marker of alcoholic hepatitis in heavy drinkers compared to 


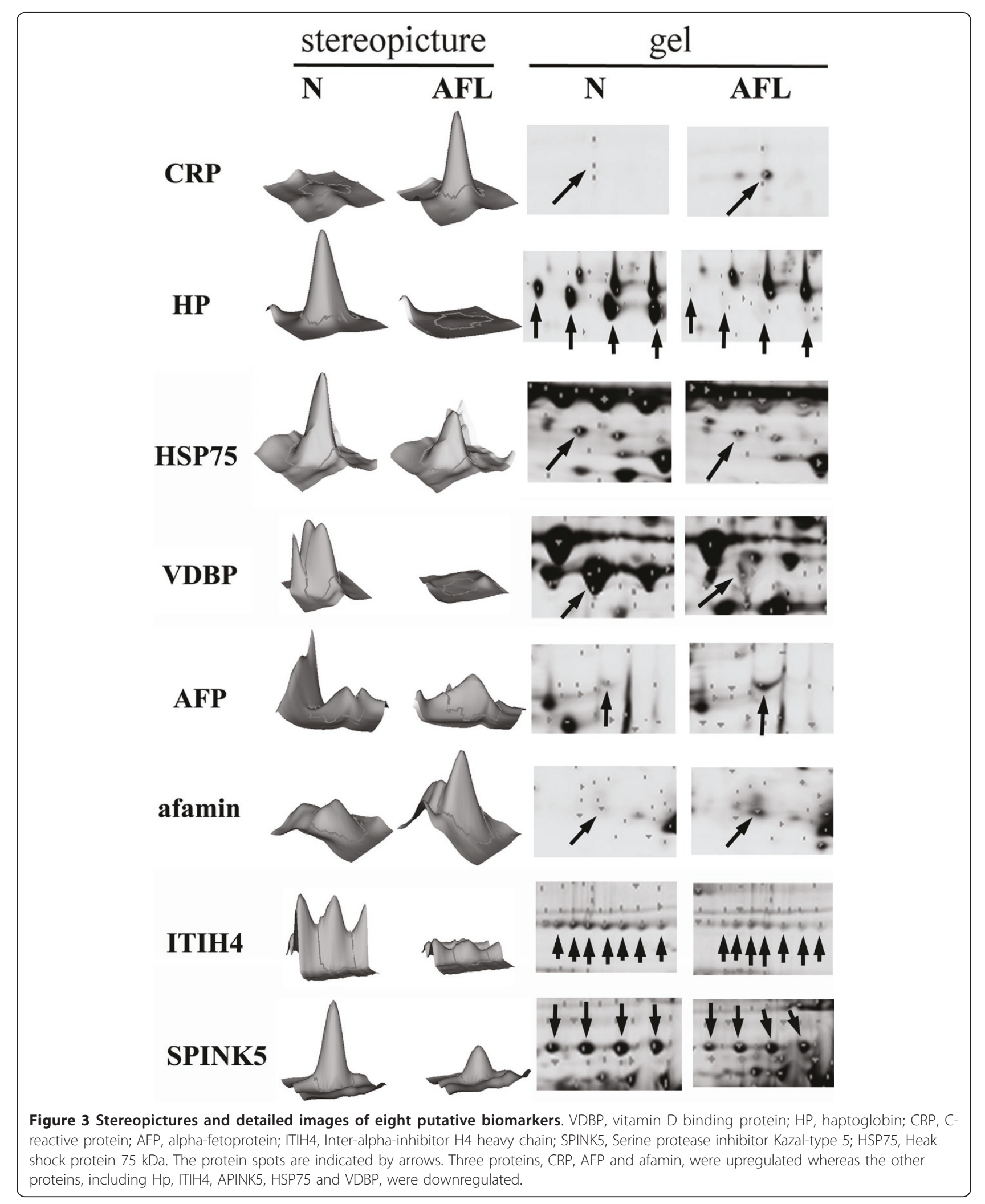


Table 2 Protein spots identified by MALDI-TOF/TOF MS

\begin{tabular}{|c|c|c|c|c|c|}
\hline Gene name & Protein name & $\operatorname{Mr}(\mathrm{Da}) / \mathrm{pl}$ & Coverage ratio & Regulation" & $p$ value \\
\hline Crp & C-reactive protein & $25452 / 4.89$ & $7 \%^{\S}$ & +4.71 & 0.02 \\
\hline Afm & Afamin & $49311 / 6.14$ & $59 \%$ & +1.64 & 0.04 \\
\hline Afp & Alpha-fetoprotein & $47195 / 5.47$ & $3 \%^{\S}$ & +1.46 & 0.03 \\
\hline $\mathrm{Hp}$ & Haptoglobin & $39052 / 6.10$ & $48 \%$ & -11.54 & 0.04 \\
\hline Gc & Vitamin D-binding protein & $53493 / 5.65$ & $4 \%^{\S}$ & -1.74 & 0.04 \\
\hline Itih4 & Inter-alpha-inhibitor $\mathrm{H} 4$ heavy chain & $103885 / 6.08$ & $48 \%$ & -1.66 & 0.03 \\
\hline Spink5 & Serine protease inhibitor Kazal-type 5 & $114816 / 8.68$ & $74 \%$ & -1.67 & 0.04 \\
\hline Trap1 & Heak shock protein $75 \mathrm{kDa}$, mitochondrial & $80639 / 6.56$ & $57 \%$ & -1.96 & 0.02 \\
\hline
\end{tabular}

${ }^{\text {s} T h o s e ~ p r o t e i n s ~ w e r e ~ i d e n t i f i e d ~ b y ~ M S / M S . ~ " ~ P r e s e n t e d ~ a s ~ u p-~(+) ~ o r ~ d o w n ~ r e g u l a t i o n ~(-) ~ c o m p a r e d ~ t o ~ n o r m a l ~ c o n t r o l s . ~}$

hepatitis unrelated to alcohol [7]. In this study, we discovered that CRP levels were elevated in AFL rats compared to healthy animals, and rats with other forms of liver diseases, such as NAFL and TAA-induced liver fibrosis. Although the use of moderate alcohol consumption can lower the level of CRP in the serum and decrease cardiovascular mortality [21], in our study the intake of high amounts of alcohol in this rodent model increased the level of serum CRP, suggesting that the intake of ethanol is positively associated with the level of serum CRP. To our knowledge, CRP is considered an inflammatory protein produced from macrophages in the liver and adipocytes [22,23]. In order to exclude elevated CRP derived from a response to gastrointestinal inflammation because of ethanol consumption, we examined protein levels of alpha1 antitrypsin, an acutephase marker $[24,25]$, determined by Western blotting, which provided a positive reference of an inflammatory response. The results showed that levels of alpha1 antitrypsin in rats among the four groups were the same (Figure 4A, D), indicating that the elevation of CRP was not due to gastrointestinal inflammation. Moreover, in vitro study revealed that ethanol can directly trigger the secretion of CRP in HepG2 cells (data not shown). Herein, the results suggest that ethanol-induced formation of fatty liver was strongly related to the induction of serum CRP in rats supplied with excess ethanol.

An increase in CRP was also reported to be associated with obesity $[17,18]$. To address our concern for the obesity issue, we also measured animal weight in all
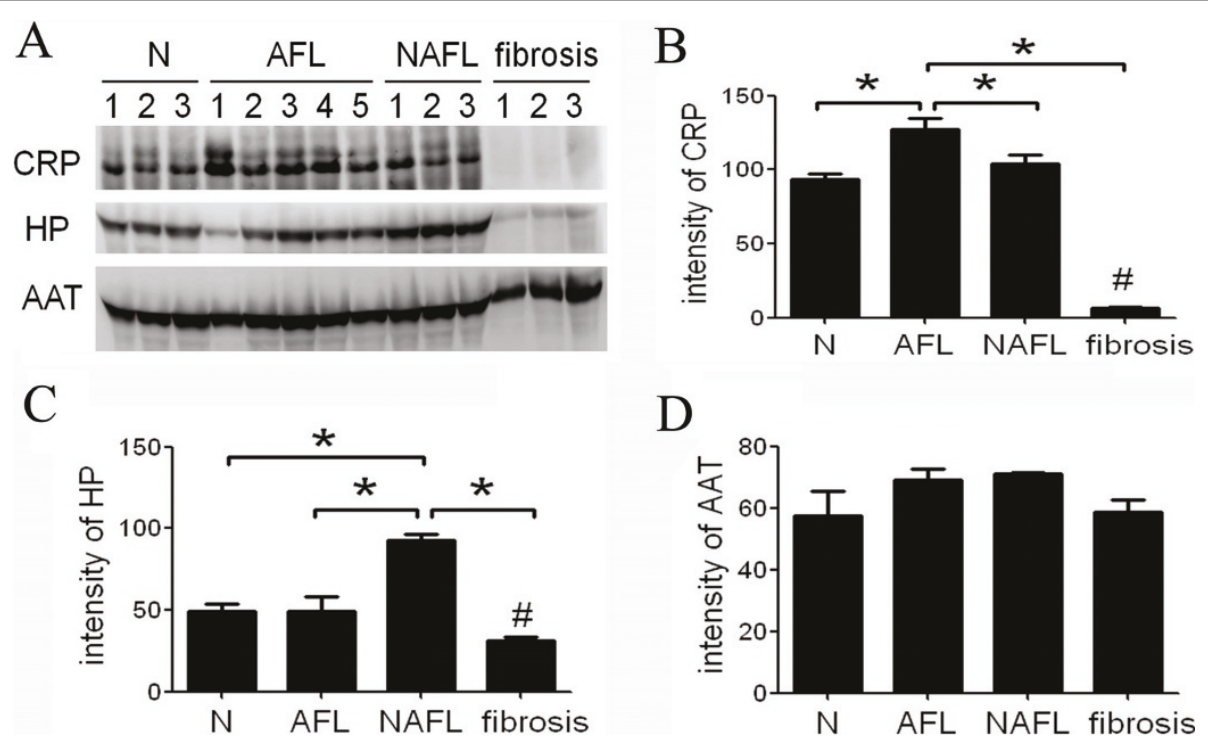

Figure 4 Evaluation of the expressions of alcoholic fatty liver (AFL) biomarkers using western blotting. (A) Confirmation of C-reactive protein (CRP) and haptoglobin (Hp) expression by Western blotting. AAT was used as an indicator represented as a positive inflammatory protein for gastrointestinal inflammation (B) The semi-quantification of the results of Western blotting. CRP increased in the serum of AFL rats compared to normal, NAFL and liver fibrosis ones, but decreased in TAA-induced liver fibrosis. (C) Hp increased in rats suffering from NAFL, but decreased in liver fibrosis compared to the controls. (D) AAT was not affected among the rats. Three individual samples of healthy controls, NAFL, and liver fibrosis, and five samples of AFL were examined by using Western blotting. N, normal controls; AFL, alcoholic fatty liver; NAFL, non-alcoholic fatty liver; CRP, C-reactive protein; Hp, haptoglobin; AAT, alph1 antitrypsin. ${ }^{*} p<0.05$, compared to healthy controls; ${ }^{*} p<0.05$ as compared to the other groups. 
Table 3 Serum concentration of C reactive protein (CRP) and haptoglobin (Hp) in clinical patients

\begin{tabular}{|c|c|c|c|c|c|}
\hline Patients $(n)$ & $\begin{array}{c}\text { Fibrosis } \\
(n, \%)\end{array}$ & $\begin{array}{c}\text { P-steatosis } \\
(n, \%)\end{array}$ & $\begin{array}{c}\text { HAI } \\
(n, \%)\end{array}$ & $\begin{array}{c}\text { CRP } \\
(\mathrm{mg} / \mathrm{L})\end{array}$ & $\begin{array}{l}\mathrm{Hp} \\
\text { (g/L) }\end{array}$ \\
\hline Healthy (16) & ND & ND & ND & $1.58 \pm 0.48$ & $1.13 \pm 0.63$ \\
\hline \multirow[t]{2}{*}{ NASH (19) } & $\begin{array}{c}F 1 \sim F 2 \\
(19,100 \%)\end{array}$ & $\begin{array}{c}\text { Stage } 0 \sim 1 \\
(7,37 \%)\end{array}$ & $\begin{array}{c}\text { Stage 0 4 } \\
(18,95 \%)\end{array}$ & ND & $0.74 \pm 0.39^{*}$ \\
\hline & & $\begin{array}{c}\text { Stage 2 3 } \\
(12,63 \%)\end{array}$ & $\begin{array}{c}\text { Stage } 5 \sim 13 \\
\quad(1,5 \%)\end{array}$ & & \\
\hline \multirow[t]{2}{*}{$\begin{array}{c}\text { HCV- } \\
\text { liver fibrosis (17) }\end{array}$} & $\begin{array}{l}F 1 \sim F 2 \\
(7,41 \%)\end{array}$ & $\begin{array}{c}\text { Stage } 0 \sim 1 \\
(15,88 \%)\end{array}$ & $\begin{array}{l}\text { Stage 0 4 } \\
(2,12 \%)\end{array}$ & $1.31 \pm 0.44^{*}$ & $0.45 \pm 0.58^{\text {*,\# }}$ \\
\hline & $\begin{array}{c}\text { F3 F4 } \\
(10,59 \%)\end{array}$ & $\begin{array}{c}\text { Stage } 2 \sim 3 \\
(2,12 \%)\end{array}$ & $\begin{array}{c}\text { Stage } 5 \sim 13 \\
(15,88 \%)\end{array}$ & & \\
\hline
\end{tabular}

The fibrotic stage was determined according to the Metavir classification. The stage of p-steatosis was determined according to the fatty change. HAl, necroinflammatory scores. NASH, non-alcoholic steatohepatitis; ND, not determined. ${ }^{*} p<0.05$, compared to healthy controls. ${ }^{\#} p<0.05$, compared to NASH. The significance was calculated according to Student's $t$-test. The data are presented as the mean \pm SEM.

groups. We observed that macrovesicular fat was apparent in the liver tissues of rats fed diets containing a high fructose content (HF-NAFL) which did not increase serum CRP. In AFL rats, macrovesicular fat was also observed, but serum CRP was elevated. Therefore, this suggests that alcohol abuse may cause fatty liver and induce high serum CRP levels, indicating that CRP may be qualified as a unique biomarker of AFL.

Administration of ethanol can elicit oxidative stress and injury to the liver $[4,26]$, and the presence of polyunsaturated fats can induce the production of cytochrome P4502E1 (CYP2E1) [27,28]. Under conditions of persistent ethanol stimulation, CYP2E1 seems to play a critical role in metabolizing and activating many toxicological substances such as reactive oxygen species (ROS) $[26,29]$. A recent study indicated that cytokines such as tumor necrosis factor-alpha and interleukin-10 in adipose tissues of acute alcoholic hepatitis patients were elevated, and were correlated with the serum CRP concentration [30], implying that inflammation caused the production of CRP. Although the mechanism of how ethanol induces CRP in serum is unclear, in this study, we discovered that ethanol consumption is an important factor positively associated with the production of serum CRP.

In addition to the increased CRP levels in AFL rats, serum Hp was also discovered to be a biomarker of AFL with reduced expression levels in the serum of AFL rats using 2D-DIGE. However, Hp was elevated in the serum of NAFL rats and even decreased in that of rats with TAA-induced liver fibrosis (Figure 4C). Previous studies reported by Chiellini's group indicated that elevated serum Hp is recognized as a marker of adiposity [31]. Our results demonstrate that $\mathrm{Hp}$ is not only increased in NAFL, but also decreased in TAA-induced and HCVinduced liver fibrosis. Furthermore, Shu et al. indicated that $\mathrm{Hp}$ was overexpressed in hepatocellular carcinoma compared to those with hepatitis B virus (HBV)-related cirrhosis [32]. However another research group led by
Dr. Lee reported that Hp levels were decreased independently in hepatic fibrosis in chronic liver disease [33]. Therefore, the level of serum Hp may vary under various pathophysiological situations or stages in clinical liver diseases. $\mathrm{Hp}$ is also used in the panel of AshTest [34] as a down-regulated protein. In this study, we found that $\mathrm{Hp}$ was a downregulated protein in $\mathrm{NASH}$ and $\mathrm{HCV}$-infected liver fibrosis although we found that $\mathrm{Hp}$ may be higher in the serum of NAFL rats. The results demonstrated that $\mathrm{Hp}$ is a reliable downregulated biomarker of NASH and liver fibrosis in clinical cases.

\section{Conclusions}

For a diagnosis of alcoholic liver disease, a biopsy is the gold standard. Current studies focusing on the discovery of a noninvasive biomarker panel for diagnosis or prognosis imply that development of a noninvasive method is urgent. CRP is considered to be a marker of atherosclerotic cardiovascular disease in clinical analysis $[19,20]$, modulating endothelial function in the process of atherogenesis [35]; therefore, we suggest that using CRP to distinguish AFL from the other liver diseases may consider the complication of cardiovascular disease. In conclusion, this is the first report to reveal new candidate biomarkers of AFL using a proteomics analysis. In this study, eight AFL-associated serological proteins were disclosed, which may be associated with AFL in rats. We suggest that CRP is suitable to serve as a candidate biomarker of AFL, and Hp is a reliable biomarker that decrease in NASH and liver fibrosis. In particular, serum CRP may be qualified to be an elevated surveillance target for early diagnosis of AFL in clinical screening.

\section{Acknowledgements}

We would like to thank Dr. Jyh-Chin Yang and Dr. Chiang-Ting Chien who kindly supported and provided the animals from National Taiwan University, Taipei, Taiwan. We also thank David Cooke from Oxfordshire, UK for helping us to revise the manuscript. 


\section{Author details}

'Institute of Biochemistry and Biotechnology, Chung Shan Medical University, Taichung, Taiwan. ${ }^{2}$ Graduate Institute of Medical Sciences, College of Medicine, Taipei Medical University, Taipei, Taiwan. ${ }^{3}$ Institute of Nuclear Energy Research, Atomic Energy Council, Taoyuan, Taiwan. ${ }^{4}$ Department of Internal Medicine, School of Medicine, College of Medicine, Taipei Medical University Hospital, Taipei, Taiwan. ${ }^{5}$ Department of Biochemistry, School of Medicine, Taipei Medical University, Taipei, Taiwan. ${ }^{6}$ Biomedical Mass Imaging Research Center, Taipei Medical University, Taipei, Taiwan. ${ }^{7}$ Division of Gastroenterology, Buddhist Tzu Chi General Hospital, Taipei branch, Taiwan. ${ }^{8}$ Division of Gastroenterology, Cheng Hsin General Hospital, Taipei, Taiwan. ${ }^{9}$ Research Center For Biomedical Implants and Microsurgery Devices, Taipei Medical University, Taipei, Taiwan. ${ }^{10}$ Neuroscience Research Center, Taipei Medical University Hospital, Taipei, Taiwan.

\section{Authors' contributions}

SLL: revised the article and designed the experiments. CCC: participated in article writing and performed most experiments, including 2D-DIGE, MALDITOF/TOF MS, and Western blotting. FDM and JS: Project leaders and corresponding authors, participated in this project in revising the article and providing opinions and interpretation of the data. SCL: provided suggestions and analysis regarding experimental outcomes as well as revised the article. CCW and CCC: performed tissue sampling and diagnosis. ASH: participated in the collection and diagnosis of clinical samples. LYC: Lab leader and article final revision, contributed to interpretation of the data. All authors read and approved the final manuscript.

\section{Competing interests}

The authors declare that they have no competing interests.

Received: 25 March 2011 Accepted: 1 August 2011

Published: 1 August 2011

\section{References}

1. Rouach H, Fataccioli V, Gentil M, French SW, Morimoto M, Nordmann R: Effect of chronic ethanol feeding on lipid peroxidation and protein oxidation in relation to liver pathology. Hepatology 1997, 25:351-355.

2. Grunnet N, Kondrup J, Dich J: Effect of ethanol on lipid metabolism in cultured hepatocytes. Biochem J 1985, 228:673-681.

3. Maharaj B, Maharaj RJ, Leary WP, Cooppan RM, Naran AD, Pirie D, Pudifin DJ: Sampling variability and its influence on the diagnostic yield of percutaneous needle biopsy of the liver. Lancet 1986, 1:523-525.

4. Dey A, Cederbaum Al: Alcohol and oxidative liver injury. Hepatology 2006, 43:563-74

5. Levitsky J, Mailliard ME: Diagnosis and therapy of alcoholic liver disease. Semin Liver Dis 2004, 24:233-247.

6. Fujimoto M, Uemura M, Kojima H, Ishii Y, Ann T, Sakurai S, Okuda K, Noguchi R, Adachi S, Kitano H, et al: Prognostic factors in severe alcoholic liver injury. Nara Liver Study Group. Alcohol Clin Exp Res 1999, 23:33S-38S.

7. Vanbiervliet G, Le Breton F, Rosenthal-Allieri MA, Gelsi E, Marine-Barjoan E, Anty R, Piche T, Benzaken S, Saint-Paul MC, Huet PM, Tran A: Serum Creactive protein: a non-invasive marker of alcoholic hepatitis. Scand $J$ Gastroenterol 2006, 41:1473-1479.

8. Gupta S, Slaughter S, Akriviadis EA, Valenzuela R, Deodhar SD: Serial measurement of serum C-reactive protein facilitates evaluation in alcoholic hepatitis. Hepatogastroenterology 1995, 42:516-521.

9. Gonzalez-Quintela A, Mella C, Perez LF, Abdulkader I, Caparrini AM, Lojo S: Increased serum tissue polypeptide specific antigen (TPS) in alcoholics: a possible marker of alcoholic hepatitis. Alcohol Clin Exp Res 2000, 24:1222-1226.

10. Hill DB, Marsano L, Cohen D, Allen J, Shedlofsky S, McClain CJ: Increased plasma interleukin-6 concentrations in alcoholic hepatitis. J Lab Clin Med 1992, 119:547-552.

11. Unlu M, Morgan ME, Minden JS: Difference gel electrophoresis: a single gel method for detecting changes in protein extracts. Electrophoresis 1997, 18:2071-2077.

12. Byrne JC, Downes MR, O'Donoghue N, O'Keane C, O'Neill A, Fan Y, Fitzpatrick JM, Dunn M, Watson RW: 2D-DIGE as a strategy to identify serum markers for the progression of prostate cancer. $J$ Proteome Res 2009, 8:942-957.
13. Ho AS, Cheng CC, Lee SC, Liu ML, Lee JY, Wang WM, Wang CC: Novel biomarkers predict liver fibrosis in hepatitis $C$ patients: alpha 2 macroglobulin, vitamin D binding protein and apolipoprotein Al. $J$ Biomed Sci 2010, 17:58

14. Kondo T, Hirohashi S: Application of 2D-DIGE in cancer proteomics toward personalized medicine. Methods Mol Biol 2009, 577:135-154.

15. Orenes-Pinero E, Corton M, Gonzalez-Peramato P, Algaba F, Casal I, Serrano A, Sanchez-Carbayo M: Searching urinary tumor markers for bladder cancer using a two-dimensional differential gel electrophoresis (2D-DIGE) approach. J Proteome Res 2007, 6:4440-4448.

16. Keshavarzian A, Farhadi A, Forsyth CB, Rangan J, Jakate S, Shaikh M, Banan A, Fields JZ: Evidence that chronic alcohol exposure promotes intestinal oxidative stress, intestinal hyperpermeability and endotoxemia prior to development of alcoholic steatohepatitis in rats. J Hepatol 2009, 50:538-547.

17. Gentile M, Panico S, Rubba F, Mattiello A, Chiodini P, Jossa F, Marotta G, Pauciullo $P$, Rubba P: Obesity, overweight, and weight gain over adult life are main determinants of elevated hs-CRP in a cohort of Mediterranean women. Eur J Clin Nutr 2010, 64:873-878.

18. Oda E: CRP may be superior to anthropometric markers of obesity. Circ 2007, 71:1332, author reply 1332-1333.

19. Martinez VB, Gonzalez-Juanatey JR: Markers of inflammation and cardiovascular disease: clinical applications of C-reactive protein determination. Am J Cardiovasc Drugs 2009, 9(Suppl 1):3-7.

20. Ridker PM: Clinical application of C-reactive protein for cardiovascular disease detection and prevention. Circulation 2003, 107:363-369.

21. Albert MA, Glynn RJ, Ridker PM: Alcohol consumption and plasma concentration of C-reactive protein. Circulation 2003, 107:443-447.

22. Pepys MB, Hirschfield GM: C-reactive protein: a critical update. J Clin Invest 2003, 111:1805-1812

23. Das T, Sen AK, Kempf T, Pramanik SR, Mandal C, Mandal C: Induction of glycosylation in human C-reactive protein under different pathological conditions. Biochem J 2003, 373:345-355.

24. Laskowska-Klita T, Czerwinska B: [Concentration of C-reactive protein procalcitonin and alpha-1-antitrypsin in blood of neonates and infants with signs of inflammation]. Med Wieku Rozwoj 2002, 6:5-11.

25. Borawski J, Naumnik B, Mysliwiec M: Serum alpha1-antitrypsin but not complement $\mathrm{C} 3$ and $\mathrm{C} 4$ predicts chronic inflammation in hemodialysis patients. Ren Fail 2003, 25:589-593.

26. Cederbaum Al, Lu Y, Wu D: Role of oxidative stress in alcohol-induced liver injury. Arch Toxicol 2009, 83:519-548.

27. Nanji AA, Zhao S, Lamb RG, Dannenberg AJ, Sadrzadeh SM, Waxman DJ: Changes in cytochromes P-450, 2E1, 2B1, and 4A, and phospholipases A and $\mathrm{C}$ in the intragastric feeding rat model for alcoholic liver disease: relationship to dietary fats and pathologic liver injury. Alcohol Clin Exp Res 1994, 18:902-908

28. Cao Q, Mak KM, Lieber CS: Cytochrome P4502E1 primes macrophages to increase TNF-alpha production in response to lipopolysaccharide. Am J Physiol Gastrointest Liver Physiol 2005, 289:G95-107.

29. Lu Y, Cederbaum Al: CYP2E1 and oxidative liver injury by alcohol. Free Radic Biol Med 2008, 44:723-738.

30. Naveau S, Cassard-Doulcier AM, Njike-Nakseu M, Bouchet-Delbos L, BarriOva N, Boujedidi H, Dauvois B, Balian A, Maitre S, Prevot S, et al: Harmful effect of adipose tissue on liver lesions in patients with alcoholic liver disease. J Hepatol 2010, 52:895-902.

31. Chiellini C, Santini F, Marsili A, Berti P, Bertacca A, Pelosini C, Scartabelli G, Pardini E, Lopez-Soriano J, Centoni R, et al: Serum haptoglobin: a novel marker of adiposity in humans. J Clin Endocrinol Metab 2004, 89:2678-2683.

32. Shu H, Kang X, Guo K, Li S, Li M, Sun L, Gan L, Liu Y, Qin X: Diagnostic value of serum haptoglobin protein as hepatocellular carcinoma candidate marker complementary to alpha fetoprotein. Oncol Rep 2010, 24:1271-1276.

33. Lee HH, Seo YS, Um SH, Won NH, Yoo H, Jung ES, Kwon YD, Park S, Keum B, Kim YS, et al: Usefulness of non-invasive markers for predicting significant fibrosis in patients with chronic liver disease. J Korean Med Sci 2010, 25:67-74.

34. Thabut D, Naveau S, Charlotte F, Massard J, Ratziu V, Imbert-Bismut F, Cazals-Hatem D, Abella A, Messous D, Beuzen F, et al: The diagnostic value of biomarkers (AshTest) for the prediction of alcoholic steato-hepatitis in patients with chronic alcoholic liver disease. J Hepatol 2006, 44:1175-1185. 
35. Pasceri V, Willerson JT, Yeh ET: Direct proinflammatory effect of C-reactive protein on human endothelial cells. Circulation 2000, 102:2165-2168.

doi:10.1186/1423-0127-18-52

Cite this article as: Liu et al: Discovery of serum biomarkers of alcoholic

fatty liver in a rodent model: C-reactive protein. Journal of Biomedical

Science 2011 18:52.

Submit your next manuscript to BioMed Central and take full advantage of:

- Convenient online submission

- Thorough peer review

- No space constraints or color figure charges

- Immediate publication on acceptance

- Inclusion in PubMed, CAS, Scopus and Google Scholar

- Research which is freely available for redistribution

Submit your manuscript at 